\title{
What do we know about Erasistratus? Part $3^{*}$
}

\author{
Dmitry A. Balalykin ${ }^{1}$ \\ 1 FSSBI "N.A. Semashko National Research Institute of Public Health" \\ 12 Vorontsovo Pole St., building 1, Moscow 105064, Russia
}

Corresponding author: Dmitry A. Balalykin (dbprof@bk.ru)

\author{
Received: 10 August 2018 Accepted: 10 September 2018 Published online: 19 December 2018
}

Citation: Balalykin DA (2018) What do we know about Erasistratus? Part 3. History of Medicine 5(3): 213-220. https://doi. org/10.3897/hmj.5.3.32484

\begin{abstract}
The writings of Galen are an important source of information about Erasistratus. A comprehensive analysis of this source material provides an idea of Erasistratus's and his followers' approaches to solving practical problems of clinical medicine. The article's author cites arguments confirming that Erasistratus's clinical practice, the basis of which was the natural philosophy of atomism, should be considered as the foundation of methodologists' teachings. Methodist physicians, guided by Erasistratus's medical postulates, needed a theory that logically explained the phenomena they observed, while for rationalist physicians theoretical medicine was the impetus for experimental studies, the results of which became its foundation.

The third part of the article presents historical and medical commentary of the Galen treatise "Treatment by Bloodletting," which, along with his two other writings - "Bloodletting, against Erasistratus" and "Bloodletting, against the Erasistrateans at Rome," contains valuable information about Erasistratus, allowing us to reconstruct his view of clinical practice and medicine in general. In his opinion, anatomical knowledge could not form the basis for reliable ideas about the structure of the human body. Anatomy and physiology were addressed by Erasistratus in a limited way, without contradicting his philosophical views. An important component of the clinical practice of Erasistratus was the rejection of venotomy, which was connected with the peculiarities of his worldview and the worldview of methodologists, the theoretical basis of which was the natural philosophy of atomism.
\end{abstract}

\section{Keywords}

history of medicine, ancient medicine, Erasistratus, Methodic doctors

In completing this analysis of the source evidence we have allowing us to form a reasonably comprehensive impression of Erasistratus's views, ${ }^{1}$ I would like to look at how they were developed by later generations of physicians. To back up my theory that significant and irreconcilable differences existed between the approaches of Herophilos ${ }^{2}$ and Erasistratus to medicine, I would

\footnotetext{
The work was done within the project of the Russian Science Foundation № 18-78-10018 "Problems of bioethics in the historical context and socio-cultural dynamics of society", carried out on the basis of FSBEI HE PRMU MOH Russia.

1 Parts 1 and 2 of this article are published in previous issues of History of Medicine (Balalykin $2018 \mathrm{a}, \mathrm{b}$ ). Further information on Erasistratus can be found in (Kudilen 1981; Lonie 1964; Wilson 1959; Dobson 1926-7; Fraser 1969; Smith 1982).

2 For details of Herophilos's views, see (von Staden 1989).
}

like to discuss another aspect of Galen's argument with the followers of Erasistratus of his day. I believe that the differences between the schools of Herophilos and Erasistratus become even clearer and deeper in the third century BC. In connection with this article, a Russian translation of a further source is being published: Galen's treatise Treatment by Bloodletting (Galen 1826a). ${ }^{3}$ This will help me to demonstrate the fundamental and irreconcilable differences between Galen, as a follower of Herophilos, and his opponents - the physicians who followed Erasistratus.

Galen wrote Treatment by Bloodletting in order to reiterate the principles underlying the use of phlebotomy.

\footnotetext{
3 A translation of this treatise will be published in Volume $\mathrm{V}$ of The Works of Galen. This article uses a translation of the text by Zoya Barzakh.
} 
Given the scarcity of therapeutic options available to ancient doctors, venesection was an issue of paramount importance.

The majority of Galen's opponents, who belonged to the school of the Methodic doctors, rejected phlebotomy outright, invoking the authority of their celebrated predecessor Erasistratus. On the other hand, some representatives of this school asserted that Erasistratus was not against its use, but doubted its effectiveness.

Galen argues with both groups. His strategy is to show, through detailed analysis of Erasistratus's writing, that he rejected phlebotomy. In this context, Galen disputes Erasistratus's arguments in favour of treatment methods other than phlebotomy. At the same time, Galen shows that the Methodic doctors claiming that Erasistratus accepted the use of venesection are wrong.

Galen argues that Erasistratus did not just exclude phlebotomy from clinical practice: his stance was rooted in a tradition originating with the works of Chrysippus of Knidos. Meanwhile, the Methodic doctors of Galen's day were either fantasists, trying in vain to vindicate Erasistratus in this context, or uneducated people repeating his errors. In any case, the great Roman physician regarded it as important to show the ignorance of the Methodic doctors' ideas on phlebotomy.

At the same time, Galen tries to support his followers and pupils. To this end, taking his argument with his opponents as a starting point, he outlines the principles underlying the correct use of this effective but extremely risky procedure.

At the start of Treatment by Bloodletting, Galen sets out the main questions doctors using the method needs to answer. The first issue they need to consider is "how many states of the body there are that call for evacuation" (Galen 1826a, p. 250). This means not only what we would call "clinical diagnosis": Galen has in mind the need not only to identify the patient's illness, but also to assess the seriousness of their condition. This leads on to the second task: to ascertain whether "evacuation" can be achieved through less invasive methods. Doctors should use bloodletting only when sure that other methods will not work. After this, their third task is to develop carefully an approach allowing them to phlebotomise "without harm" (Galen 1826a, p. 250).

Some patients, "because of their general habit of body," may not be able to cope with this arduous surgical intervention. The classification of types of phlebotomy writes Galen, is naturally determined by the topography of the vessels to be opened, as Hippocrates conjectured. Adhering to the Hippocratic principle of an individual approach to patient treatment, Galen writes: "And after all these, there is also the fact that in some patients it is better to remove blood only once, but in others to perform the operation known as epaphairesis; in some to evacuate to loss of consciousness, but in others to shun this as the greatest of evils" (Galen 1826a, p. 252).
Galen sees in Hippocrates's apologia a convenient pretext for pointing out the weakness of his opponents' arguments: "One ends up not knowing whether to hate more the wickedness of the accursed sophists, when they eagerly contrive new theories which they know perfectly well to be false, or their conceit of wisdom, when they make up arguments to discredit the most useful remedies, about which, in fact, they know nothing" (Galen 1826a, p. 252). Such an approach makes sense: the Methodic doctors of Galen's day regarded this tradition as supported by the authority not only of Erasistratus, but also of his legendary predecessor Chrysippus of Knidos.

Galen reminds readers of his other works on this issue:4 "I have been obliged to discuss these in another work, to demonstrate to neophytes that Erasistratus did not use phlebotomy; for it is better that they should believe this than that they should phlebotomise every single one of those patients for whom Erasistratus ordered fasting" (Galen 1826a, p. 254).

The great Roman physician states that the use of any pharmaceutical remedies or therapeutic intervention should be based on individual indications: "The book also shows that patients will derive the greatest benefit from the remedy when it is appropriately used" (Galen 1826a, p. 254).

First and foremost, Galen advises assessing whether methods of "evacuation" other than phlebotomy can be used (Galen 1826a, p. 255). "All objects of enquiry," he writes, "have two instruments of discovery - reason and experience." Accordingly, there are two ways for doctors to resolve problems they encounter in their work: through "reason itself, starting from commonly held notions" or through scientific method, bearing in mind preceding tradition. Here, Galen gives the example of the work of a geometer and astronomer calculating the sizes of the sun and the moon. He insists that the decision whether to perform phlebotomy needs to take account of "many things that have been demonstrated in other works." Through these examples of mathematical calculations, and by reference to his previous books, Galen reminds readers of the basic principles of his methodology. This part of Treatment by Bloodletting may be compared to the "materials and methods" section of a modern academic paper on scientific matters.

It is no accident that the next chapter of Galen's treatise starts with a statement of what he sees as a basic principle of medicine: "The function of the art of medicine is both to restore all the natural functions of the parts of the body when they have been corrupted, and to preserve them once they have been restored. Now these corruptions follow upon the natural state;

\footnotetext{
For commentaries on Bloodletting, against the Erasistrateans at Rome (Galen 1826b) and Bloodletting, against Erasistratus (Galen 1826c), see (Balalykin $2018 \mathrm{a}, \mathrm{b}$ ).
} 
we must therefore both preserve this state while it is still in existence, and restore it when it has been corrupted" (Galen 1826a, p. 259). To properly understand the subsequent text, it is important to remember Galen's other works - primarily Natural Capacities, Types of Diseases, Causes of Diseases, and Distinctions in Symptoms. ${ }^{5}$ Galen gives a brief but informative description of the pathophysiological causes of a "plethos" of a humour in the body. He discusses the difference between the structure and function of the homoiomerous and complex (organs) parts of the body. Plethoric conditions give rise first to functional and then, in time, organic disorders. Organic symptoms develop as these disorders get worse: "Thus we may have a feeling of heaviness, or some sort of ulcerous sensation, which is confined to the head; or the temporal muscles may be in spasm, either as an isolated condition or in association with an increase in heat. Often, again, we have a sensation of weight in relation to the liver, spleen, stomach, ribs or diaphragm" (Galen 1826a, p. 261). Sometimes, these pains are "the result of the concerted attack of a plethos of humours... with or without an associated flux of humours" (Galen 1826a, p. 261). Without doubt, all these cases require the plethos to eliminated, but "phlebotomy is not needed at all; it is enough to purge, rub and bathe [the patient], and to anoint him with some diaphoretic drug” (Galen 1826a, p. 261-262).

Assessing a plethoric condition entails, inter alia, an understanding of which particular humour dominates in the development of a particular pathological condition. To explain the logic behind the use of phlebotomy, Galen discusses the function of the blood and its possible disorders: "Not only do the parts of the animal derive their nourishment from the blood, but the innate heat also owes its continuance to it, just as the fire on the hearth does to the burning of suitable logs, by which we see whole houses made warm. And just as this fire is sometimes harmed if faggots are piled on it indiscriminately, and sometimes if, although not too abundant, they are very damp, or if none are put on it at all, or very few - so also the heat in the heart sometimes becomes less than normal because of the excess of blood, or a great shortage of it, or a cold quality; and sometimes more, either because of a warm quality of the blood, or a moderate excess of it" (Galen 1826a, p. 262).

Doctors may encounter states of heat and cold in their patients. "Unnatural heat or cold," writes Galen, can "originate in two ways: sometimes as a result of hot or cold humours, sometimes from dyscrasia alone" (Galen 1826a, p. 263). At the same time, the causes of such a state do not have to be located in the part of the body affected by the disease. For example, vascular

\footnotetext{
A Russian translation of Natural Capacities will be published in Volume V of The Works of Galen. For the other three treatises mentioned, see (Galen 2015, p. 578-604, 639-663 and 700-727).
}

diseases may lead to poor digestion in the belly. Badly digested food undergoes corruption, may become "too phlegmatic or too bilious," and, getting into the blood, pathologically affects it: "the blood that is putrefying will, therefore, be hotter" than it naturally is. Consequently, "Since the adjacent parts are heated at the same time by this perceptible heat, all the surrounding region will be heated, together with the parts thus affected, by the sharp and biting heat, since this is the nature of the heat from putrefaction. If, now, the part thus heated is an important one, capable of extending its own heat to the heart, either because it is near it, or is a vital organ, or because it is hot, it will heat that organ (the heart), inasmuch as the heart is very hot by nature" (Galen 1826a, p. 264). This "heating" of the body, caused by pathologically hot blood, is called "fever" in the Greek medical tradition.

What does Galen see as lying behind the development of local symptoms that may be serious enough to dominate the patient's overall condition? He gives a clear answer to this question: "Sometimes the plethos of blood, before it has begun to putrefy, arrives in force at some part, either mortifying it completely, so as to destroy its function, or doing it notable damage. The apoplexies originate in this way, by a concerted rush of a quantity of blood to the governing centre of the animal" (Galen 1826a, p. 265). Galen believes that an influx of pathologically altered blood may also lead to other, no less serious conditions, such as abnormal swellings. The only question is what sort of blood affects the organ in question: "When the blood that has descended on the part is too thick and melancholic, the swelling that results is scirrhous, just as it is flabby when the flux is more phlegmatic. When the flux is bilious it leads to erysipelas" (Galen 1826a, p. 265).

Thus, Galen explains when phlebotomy can performed: when an excess (a pathological quantity) of altered blood affects a particular part of the body, causing a serious illness. Treating a disease requires addressing this pathogenic influence, so phlebotomising makes sense from a pathogenetic point of view.

Galen is a consistent advocate of an individual approach to patient treatment. In stating the need to evacuate the patient's body, he lists the factors to take into account when deciding the clinical approach: the patient's physical and mental condition, what food and drink the patient consumes, what exercise the patient has taken, and so on (Galen 1826a, p. 267). Doctors, he says, should pay particular attention to external factors - the season, environmental features, and other such circumstances that may affect the balance of the tetrads of the humours, substances and elements.

Galen's logic is clear: phlebotomy is a powerful therapeutic remedy that can do good, but can also do harm. In certain circumstances, phlebotomy is dangerous. The great physician gives the example of a patient 
"rather cold" by nature who, following venesection in the presence of external factors exacerbating their condition (cold winter weather), may "suffer dreadfully from chilling of the whole body." Such a patient requires "rubbings and anointings... and drinks that cut through the glutinosity of the humours" - anything except phlebotomy (Galen 1826a, p. 270).

It was Hippocrates who introduced into medical practice the idea that the severity of certain diseases depended on the season. For Galen, these theoretical ideas were fundamentally important, all the more so since the idea that the environment influenced the development of a plethoric condition appeared entirely logical. For example, Galen states that patients suffering from attacks of epilepsy or apoplexy feel best in the spring. The same applies to those suffering from haemoptysis, pleurisies, pneumonia or lung conditions, accompanied by intermittent attacks of synanche. Accordingly, phlebotomy aimed at addressing a pathological plethos in such patients is best performed at the beginning of spring. Galen's idea is to choose the season when the patient, in general, is at their best, giving them enough time to recover after the treatment. If the patient's condition is usually worst in summer, the best time for the operation is the start of spring. This approach should also be used in treating patients with various other extremely serious chronic diseases: "This applies also to those in whom haemorrhoids have been suppressed, and particularly if they appear somewhat melancholic. And as for those who go down every year in summer with plethoric diseases, they too should be evacuated at the onset of spring. Similarly those who are seized in spring itself with such diseases, some having weak eyes, or being subject to the diseases called scotomatic - these also need to be evacuated at the beginning of spring, after we have first considered what sort of concourse of humours they have. This is because some accumulate the bilious humour more than the rest, others the melancholic or phlegmatic variety, while others again accumulate all of them equally; in these, blood is said to be in excess. You will evacuate all these, as you will also your gouty and arthritic patients, at the beginning of spring, either by purging or by phlebotomising. I have cured many who had already been troubled on and off for two or three years with pains in the feet, either purging away the excessive humour at the beginning of spring, or removing blood" (Galen 1826a, p. 271-272).

Galen sees the human body as an integral, functional and organic combination of parts of the body, which interact. "Bad blood, or some other humour" does not remain in the affected organ, but "must arrive at some nearby part" of the body. In other words, toxicosis is always a generalised process within the body. It is also worth noting Galen's idea that some parts of the body may be "stronger" than others. Doctors today would refer to this as the patient's susceptibility to a particular organic pathology. Galen explains: "This is why the weakest parts of all are the first to be seized with diseases due to residues" (Galen 1826a, p. 274).

Galen states that there are four natural faculties: attractive, retentive, excretory and transformative. Accordingly, the strength or weakness of these faculties in his system determines susceptibility to a particular condition. With regard to the clinical aspects of the use of phlebotomy, susceptibility to plethos (i.e. to the pathological absorption of a humour) is an important factor. According to Galen, this is determined by the transformative faculty. Here, he regards the glands, followed by the spleen and the brain, as the most likely to receive the excess: "The brain is similar to these, or perhaps even better adapted to receive the flow. It has the advantage of them by reason of its structure, which is adapted for the excretion of what it has received, for it has capacious ventricles discharging by downward passages. In those people in whom the lung, spleen and brain are stronger than the fleshy parts, the fluxions go to the glands and flesh, with the weakening of the whole constitution of the body, as happens in the rheumatic diseases" (Galen 1826a, p. 275-276).

With a plethoric condition, the art of prognosis becomes extremely important for a doctor. Galen writes that changes in the patient's condition can be assessed so as to be ready to evacuate the excess humour when necessary, by "either purging or phlebotomising" (Galen 1826a, p. 276).

Galen mentions a recommendation given by Hippocrates in the appendix to On Regimen in Acute Diseases: ${ }^{6}$ "to use phlebotomy when the disease is severe and the patient in the prime of life and strong." Analysing the practical aspects of the use of phlebotomy, and developing Hippocrates's idea, he describes this approach in his own words: "It is enough to take into consideration the patient's age, together with his strength, so that the three factors upon which the decision is made are the severity of the disease, whether present or expected; the stage of life in the prime, and the strength of the faculties" (Galen 1826a, p. 278).

Galen opposes those physicians who (like Menodotus, whom he mentions) made plethos indication in itself for phlebotomy. The possibility of the patient's condition worsening, with plethos and the likelihood of their disease reaching a kind of peak (or height) as a result of a deterioration of this condition should compel the doctor to contemplate the prospects for phlebotomising. Galen's logic becomes completely understandable to professionals today, and not dissimilar from their thinking, if one imagines a specific clinical situation whereby a patient suffers a haemorrhagic stroke ("apoplexy" in the language of ancient medicine).

\footnotetext{
6 For a Russian translation of this work by Hippocrates, see (Hippocrates 1936 , p. 393-420).
} 
Seeing the deterioration in the patient's condition, experienced doctors skilled in the art of prognosis understand that the peak of the disease (a state of advanced symptoms of irreversible brain damage) is near. They can then turn to phlebotomy, producing an immediate reduction in the pressure from the excess blood on the brain. This will give the patient a chance to avoid the worst outcome, preventing the illness from reaching its peak, when the neurological consequences become irreversible.

Galen discusses the art of prognosis and the need for an individual approach in each clinical case: "If it appears that it will be severe, we shall invariably phlebotomise, even if none of the signs of plethos is present, having regard to the patient's age and the region and his faculties.”

It is for this reason that Galen adds an important caveat regarding child and elderly patients. The aged, in his view, usually do not have enough strength, meaning that phlebotomy is extremely rarely suitable for elderly patients. Galen's scepticism regarding performing this arduous procedure on elderly patients is obvious, and is particularly understandable in light of his earlier list of illnesses against which phlebotomy is particularly effective.

Galen makes an interesting observation on phlebotomising children. Unlike many of his opponents, he finds this entirely reasonable, on the grounds that a growing body often has a much greater capacity to fight disease than an adult's: "Some physicians have thought that strength was likewise absent in children, but they judged wrongly, as I have shown in other works.” Additionally, an exception should be made for children within the context within standard prognosis (Galen $1826 \mathrm{a}$, p. 279). This is by no means the only caveat in this work, and I think this is worth highlighting.

On the other hand, a patient in the prime of life may be extremely weakened as a result both of an immoderate lifestyle and of developing a serious clinical condition. In this case, even where the doctor can clearly identify plethos, and even where there is a critical accumulation of crude humours, phlebotomising may be inadvisable: "The sign that patients are unable to bear phlebotomy is this: the complexion of the whole body lacks the colour that indicates an abundance of blood, and at the same time the pulse shows an abnormality in respect of force and of volume, characterised by a predominance of feeble and small beats" (Galen 1826a, p. 279).

Galen highlights the need to accurately determine the dosage of medicine or preparation being administered by the doctor. This is difficult: even experienced doctors with a good understanding of which medicine to use and when to use it, may miscalculate the required dosage.

Phlebotomy, where the volume of blood drawn is always under the doctor's control, is a different mat- ter. Galen advises focussing in good time on drawing it gradually and constantly monitoring the patient's condition in order to determine how much phlebotomy to do: "Hence it is better, if there is no urgency, to make the first bloodletting rather small, and to perform a second one - and, if you like, a third - later. Thus in cases where extensive evacuation is called for, but the faculties are not strong, it is appropriate to divide up the evacuation, as you must have seen me doing in patients who have a plethos of somewhat crude humours. After I have let a little blood I immediately give some melicratum, nicely cooked, with one of the attenuating drugs, hyssop or organy or even mint or pennyroyal; one may also give oxymel or oxyglycy with melicratum. After this, I take blood again, sometimes on the same day, sometimes on the next; at which time I again give one of the drugs mentioned, in the same way, and remove blood once more; and on the third day I repeat the same process twice. When, however, there is a plethos of seething blood, enkindling a very acute fever, there is need for copious evacuation. One must try to evacuate this blood to the point of fainting, keeping an eye on the strength of the faculties. I know, for instance, of some doctors who take six cotyles, either all at once or spread over two, three or four days, and sometimes on the very first day of the illness, in cases where fever had set in about nightfall or in the course of the night, and the food taken the previous day had been well digested" (Galen 1826a, p. 286-287).

In general, writes the great Roman physician, fever requires a particular approach to phlebotomy. Galen associates fever with the development of "a plethos of seething blood." It is an acute condition with an unfavourable prognosis that requires immediate action, "even during the night." Galen calls the idea of some of his colleagues that phlebotomy should be performed at a particular time of day ("between the second hour of the day and the fourth or fifth") "laughable." Evidently, this misconception applied specifically to bloodletting, but not to other treatment methods: Galen emphasises that these doctors perform enemas and other procedures "as the disease requires," at any time of day. Clearly, he is referring here to specific errors by doctors whom he knew well: he is not hostile to them, but takes the opportunity to criticise, while tactfully not naming them.

Galen regards loss of consciousness in a patient as a sign that a critical volume of blood has been drawn. He describes how patients have lost consciousness, suffered chills (in contrast to the preceding fever) and, after resting, recovered. When phlebotomising, the patient's pulse should be constantly monitored, otherwise there may come a time when the procedure becomes dangerous. Galen gives an example: three doctors phlebotomised two men and a woman, each suffering from fever. Because they failed to monitor 
their pulses, the patients lost consciousness and died (Galen 1826a, p. 288-289). In effect, the doctors, not knowing how to perform phlebotomy properly, killed their patients!

Galen then sums up his arguments so far, re-emphasising two factors that physicians need to take into account - the severity of the disease, and the patient's reserves of strength: "The severity of the disease, then, together with the strength of the faculties, were the chief indications for phlebotomy: the former by showing what must be done, the latter by not prohibiting it. (This is what some of the newer physicians call a contraindication.)" (Galen 1826a, p. 289-290). Both these criteria need to be met: the disease has to be serious enough to necessitate bloodletting, while the patient must have the strength to cope with the operation and the subsequent recovery period. If they are, phlebotomy can be performed. The patient's constitution is described using the theory of humours. Phlebotomy is suitable for "those who have large veins, who are moderately slender and neither fair nor soft-fleshed." In other cases, doctors should think seriously about whether it is necessary. They should also be very cautious about phlebotomising children under fourteen. Many doctors of Galen's day, as can be seen from a number of his statements, believed that children should not be phlebotomised in principle. Accordingly, Galen makes it clear when the treatment may be performed with complete confidence: when the child is by nature "abounding in blood," the weather conditions are favourable, and the disease is severe ("if there is a lurking danger of peripneumonia, synanche, or pleurisy") (Galen 1826a, p. 290).

The control mechanism while performing the operation is observation of the pulse. First, "the strong, regular pulse" is a good sign that phlebotomy is possible. Second, the pulse should be monitored during the procedure: it is an indicator of the patient's condition: "You must stop the bleeding immediately if [the pulse] changes, either in volume or by developing any sort of abnormality. What more is there to say about the change towards indistinctness, since you have learned that in this quality there is a sound criterion of the strength, as well as the weakness, of the faculties?" (Galen 1826a, p. 292).

If the fever is sufficiently intense, the doctor may observe inflammation near the opened vein itself (Galen's idea here makes perfect sense to doctors today, who are familiar with the generalised nature of toxicosis). The great Roman physician states that the nature of the flow of blood observed by the doctor may change during phlebotomy, as Hippocrates had noted in On Regimen in Acute Diseases. If the seat of inflammation focus lies hidden inside the body and cannot be accessed directly, choosing the appropriate vascular topography may, according to the teaching of Hippocrates and Galen, ensure such access. If, for example, the blood flowing from the vein becomes darker and thicker after a while, this, according to these giants of ancient medicine, indicates that blood flowing directly from the seat of inflammation has reached the site of the cut.

Galen advises using two criteria in deciding how much blood to draw: the patient's nature, and the weather conditions at the time of the treatment. In addition, if the climate is hot, and the combination of humours determining the patient's constitution is "damp and hot," the patient should be given extra food. In such cases, a large amount of blood may be drawn. In contrast, in the case of "soft-fleshed and fair patients" at a cold time of year the amount should be very moderate. Galen emphasises that assessing whether enough blood has been drawn also requires an individual approach: "Hence we cannot lay down in black and white a fixed amount to be removed in each of the conditions mentioned. I have known myself remove as much as six pounds of blood from some patients, extinguishing the fever forthwith and doing the faculties no harm; yet in others one and a half could not be taken without some slight injury to the faculties, and if two had been taken from these patients, the gravest damage would have resulted. Thus I know that I have sometimes removed as little as one pound with benefit, and sometimes even less, from a vein in the elbow, ham or ankle, as I have also done from the veins at the greater canthi of the eyes or under the tongue. There is not usually a notable flow; nor is there if one cuts a vein in the foot or in the finger-tips, as those do who intend to treat the spleen by opening a vein alongside the second of the small fingers. More of this later" (Galen 1826a, p. 294-295).

In Treatment by Bloodletting, Galen returns from time to time to a fundamental recommendation regarding the phlebotomy procedure: to choose the optimum topography of the vessel being opened. Ideally, the bleeding should, as the great physician puts it, take place "kat' ixin" ("on the corresponding side"). In other words, the site of the bleeding should be as close as possible to the affected part of the body. This is not always possible in real-life clinical conditions, but " $k a t$ ' ixin" must mean (at the very least!) "on the same side as the lesion" (Galen 1826a, p. 296). Galen gives examples clarifying this recommendation: "So also when the spleen is affected, incision of the vein in the ring finger of the left hand is of benefit, just as it would be if you were to cut the inner vein at the elbow; for evacuation of blood from the left hand helps a disordered spleen considerably. It is better, however, not to let out the appropriate amount at one operation, but to spread it over two days... In pleuritic patients, phlebotomy on the same side as the affected rib has often shown the clearest benefit, while if it is on the opposite side, the benefits are either quite indefinite or are seen only after some time has elapsed. Phlebotomy on the affected side has often checked, within an hour, the severest pains in the eye, when the vein known as the humeral is cut... 
When, on the other hand, the ribs, lung, diaphragm, spleen or liver and stomach are involved, the vein is the one that passes through the armpit to arrive at the elbow joint; cut this, particularly the inner vein, or failing that the vein branching from it towards the flexure of the joint" (Galen 1826a, p. 296-298).

Sometimes, doctors need to take a creative approach to deciding which vein to open in order to treat the affected part of the body. Galen notes that the patient's anatomy can impede access to the vein: not everyone has prominent, easily accessible veins. In this case, the physician should open a vein that is accessible and is located as close as possible to the one that would ideally be opened, were that possible.

Galen gives general guidelines on choosing where to phlebotomise: a prominent vein should be located below the affected part of the body. For eye or throat conditions, attacks of apoplexy, and so on, he recommends opening the humeral vein, or a branch of it, depending on the size and the ease of access. Bloodletting necessitated by a pathology of organs in the pelvic region should be performed by cutting the vessels at the hams and ankles. Kidney conditions are a special case: Galen divides them into "the condition they specifically call nephritis" and others, associated with plethos or recent inflammation. For the former, the great Roman physician believes that the bloodletting should be done near the elbow; for the latter, blood should be drawn from vessels in the legs. For conditions of the uterus, he writes, bloodletting from shin veins is effective, especially when performed in stages over three or four days. These should preferably be combined with "a reducing diet" and the use of special drugs, recipes for which Galen also describes here (Galen 1826a, p. 302-304).

The great physician identifies three forms of venesection: incipient inflammations should be treated through "revulsion," and chronic ones through "evacuation"; where the condition is advanced, the doctor should evacuate at least the blood from the parts of the body located in the immediate vicinity of the affected organ.

Galen makes it abundantly clear that bloodletting is an extreme surgical intervention that is highly effective if performed to save a life. When such circumstances arise depends on the progress of the disease and the patient's capacity to undergo the treatment. No artificial link should be drawn between when the operation should be performed and the chronology of the disease: bloodletting performed other than in an emergency or urgent situation may prove at best useless and at worst a danger to the patient's life. The disease may progress in such a way as to necessitate operating immediately or after a certain time, but in any case the surgery should be performed only on the basis of the actual clinical picture ("even if it is the twentieth day from the onset").
Galen regularly returns to an idea set out and explained by him in The Art of Medicine: ${ }^{7}$ physicians merely assist nature, so they need to take account of their patients' reserves of strength and the conditions (primarily weather) they live in. As such, he advises phlebotomising when factors conducive to saving the patient's strength and to their capacity for recovery are present: to perform the operation in the morning, when the patient has had the chance to get a good night's sleep, and to measure the volume of blood drawn, while not forgetting to prescribe additional food, recuperative walks, and so on (Galen 1826a, p. 311-312).

Another extremely important question is whether bloodletting can be performed by cutting an artery rather than a vein. For Galen, this is something that it is logical to ask, "since when hot and spirituous blood causes trouble through being crowded into the arteries, there is need for the arteries common to the affected parts to be cut" (Galen 1826a, p. 313). At the same time, he warns against the obvious danger: bleeding from an artery is much harder to staunch. A patient is much more likely to die from uncontrollable bleeding when an artery is cut than in venesection. Galen also mentions cases known to him where attempts to staunch arterial bleeding by ligating have resulted in gangrene of a limb.

To conclude this discussion on Erasistratus, I would like to note the following aspects.

The evidence we have reveals significant differences between the views of Herophilos and Erasistratus on medical theory and practice.

Galen's works, in particular Bloodletting, against the Erasistrateans at Rome, Bloodletting, against Erasistratus, and Treatment by Bloodletting, indicate that Erasistratus engaged in experimental research into anatomy and physiology, but it is notable how often his statements are contentious: he proceeded to experimental verification of his hypotheses in real life either later or not at all.

I believe that Erasistratus's views were demonstrably based on atomistic natural philosophy. For atomists, anatomical dissections were not crucial to clinical practice.

It is highly likely that Straton of Lampsacus was a pupil of Erasistratus. This explains the "elements of corpuscular theory" in Straton's views.

The development of Erasistratus's ideas shows that the celebrated Alexandrian physician cannot be regarded as an advocate of an experimental approach to studying human anatomy and physiology. Furthermore, I will risk suggesting that his influence on the emergence of the school of the Empiricist doctors and on the development of the anti-Hippocratic tendency

\footnotetext{
For a translation of this treatise into Russian, see (Galen 2015 p. 172-230).
} 
in ancient medicine from the third century BC to the second century remains underestimated.

Phlebotomy was an important element in the therapeutic arsenal of the Hippocratic physicians, whose worldview was informed by Platonic and Aristotelian natural philosophy. The Hippocratic physicians regarded this operation as pathogenetically justified. The Methodic doctors of Galen's day categorically

\section{References}

Balalykin DA (2018a) What do we know about Erasistratus? Part 1. History of medicine 5(1): 3-13.

Balalykin DA (2018b) What do we know about Erasistratus? Part 2. History of medicine 5(2): 154-167.

Dobson JF (1926-7) Erasistratus. Proceedings of the Royal Society of Medicine 20: 825-832.

Fraser PM (1969) The career of Erasistratus of Ceos. Rendiconti del Istituto Lombardo 103: 518-537.

Galen (1826a) De curandi ratione per venae sectionem. Claudi Galeni Opera Omnia. Ed. C.G. Kuhn. Vol. 11. Leipzig: Knobloch. P. 250316. (Cod: 10,398: Med.)

Galen (1826b) De Venae Sectione adversus Erasistrateos Romae Degentes. Ed. C.G. Kuhn. In: Claudii Galeni Opera Omnia. Vol. 11. Leipzig: Knobloch (repr.: Hildesheim: Olms, 1965). P. 187-249. (Cod: 9, 371: Med.).

Galen (1826c) De Venae Sectione Adversus Erasistratum. Ed. C.G. Kuhn. In: Claudii Galeni Opera Omnia. Vol. 11. Leipzig: Knobloch (repr. Hildesheim: Olms, 1965). P. 147-186. opposed bloodletting, and I believe that this rejection can be said to reflect a continuation of the tradition of Erasistratus. Furthermore, within the atomistic worldview there was no rational basis to bloodletting. Attitudes to phlebotomy reveal the systemic nature of the contradictions between the clinical practice of the Rationalist doctors and that of the followers of Erasistratus.

Galen (2015) Sochineniya. [Works]. Vol. II. Edited, compiled, introduced, and annotated by D.A. Balalykin. Moscow: Prakticheskaya meditsina. 800 p. (In Russ.)

Hippocrates (1936) Izbrannye knigi [Selected books]. Transl. from Greak V.I. Rudnev. Moscow: Biomedgiz. 736 p. (In Russ.)

Kudlien F (1981) A new testimony for Erasistratus? Clio Medica 15: 137-147.

Lonie IM (1964) Erasistratus, the Erasistrateans, and Aristotle. Bulletin of the History of Medicine 38: 426-443.

Smith WD (1982) Erasistratus's dietetic medicine. Bulletin of the History of Medicine 56: 398-409.

von Staden H (1989) Herophilus: The Art of Medicine in Early Alexandria. Cambridge: Cambridge University Press. 666 p.

Wilson LG (1959) Erasistratus, Galen and the pneuma. Bulletin of the History of Medicine 33: 293-314.

\section{About the author}

Dmitry Alekseevich Balalykin - Doctor of Medical Sciences, Doctor of Historical Sciences, Professor, Chief research fellow at N.A. Semashko National Research Institute of Public Health, Moscow. Email: dbprof@bk.ru Balalykin DA: ORCID 0000-0002-1813-8206 